\title{
Oral cavity cancer management during the COVID-19 pandemic
}

\author{
Joo Yong Park, DDS \\ Section Editor of JKAOMS \\ Oral Oncology Clinic, National Cancer Center, Goyang, Korea
}

Since the World Health Organization classified coronavirus disease 2019 (COVID-19) as a pandemic infection on March 11, 2020, it has spread rapidly across the globe. The cumulative number of confirmed infected cases has reached $66,383,984$, with $1,531,869$ deaths worldwide as of December $8,2020^{1}$. The spread of COVID-19 has not decreased and continues to get stronger.

Despite the controversy over its safety and efficacy, vaccines for severe acute respiratory syndrome coronavirus 2 (SARS-CoV-2) have been developed and inoculations have begun, allowing hopes that the pandemic will be addressed. However, there are concerns that human lives will continue to be affected by SARS-CoV-2.

Life changes due to these new risks also are affecting patient care. The field of oral and maxillofacial surgery is a representative area with a high risk of propagation of COVID-19 due to exposure to the upper airway and respiratory droplets. The threat of COVID-19 requires changes in the way we treat oral cavity cancer.

However, it is not easy to implement widespread, immediate changes for oral cavity cancers, as the diagnosis and treatment methods are linked to patient survival and quality of life.

COVID-19 pandemic can affect the prognosis of oral cavity cancer because it causes detection and diagnosis to be delayed. Even if a patient is symptomatic, it is likely that the diagnosis will be delayed due to their reluctance to visit the hospital during the current COVID-19 pandemic situa-

\footnotetext{
Joo Yong Park

Oral Oncology Clinic, National Cancer Center, 323 Ilsan-ro, Ilsandong-gu, Goyang 10408, Korea

TEL: +82-31-920-1264 FAX: +82-31-920-1275

E-mail: slowp@ncc.re.kr

ORCID: https://orcid.org/0000-0002-0969-151X

(c) This is an open-access article distributed under the terms of the Creative Commons Attribution Non-Commercial License (http://creativecommons.org/ licenses/by-nc/4.0/), which permits unrestricted non-commercial use, distribution, and reproduction in any medium, provided the original work is properly cited. Copyright (C) 2020 The Korean Association of Oral and Maxillofacial Surgeons. All rights reserved.
}

tion. Diagnostic delay of oral cavity cancers can be related to advanced-stage tumors and poor prognoses ${ }^{2}$.

Halboub et al. ${ }^{3}$ suggested that COVID-19 testing should be utilized for opportunistic screening of oral cancers, making it a cost effective and feasible approach. This is a difficult time which we have never experienced before, but we need a change of ideas, like the one suggested above, that can turn this situation into an opportunity.

The COVID-19 pandemic has resulted in delayed surgical treatment, resulting in use of non-surgical treatment options for oral cavity cancer.

The American Academy of Otolaryngology-Head \& Neck Surgery has recommended that surgeons delay elective cases to allow for improved safety of staff and patients, preservation of critical personal protective equipment, and expansion of hospital capacity during the COVID-19 pandemic ${ }^{4}$. Gupta et al. ${ }^{5}$ recommended delaying or postponing surgery in patients with low-grade tumor but stated that delaying surgery of oral cavity cancer for 1 or 2 months may lead to more extensive surgery or inoperability.

It has been established that increase in the duration of time between diagnosis and definitive therapy is associated with decreased overall and disease-free survival. Additionally, delays in surgery may result in increased morbidity and mortality $^{4}$.

Moon et al. ${ }^{6}$ reported that the mean number of days spent in the hospital was 19.2 days (range, 1-98 days) in 352 patients with confirmed SARS-CoV-2 infection. According to their report, if a patient diagnosed with oral cavity cancer is confirmed to have contracted COVID-19 before cancer treatment, he or she will spend more than 19.2 days (range, 1-98 days) without receiving treatment for oral cancer.

If it is necessary or inevitable to postpone the surgery, other available treatment options must be considered. Forner et al. ${ }^{7}$ conducted meta-analysis and reviewed on nonsurgical management of resectable oral cavity cancer in the wake of COVID-19. They concluded that primary radiotherapy and 
chemoradiotherapy were inferior to surgical management for oral squamous cell carcinoma. Nevertheless, in this special COVID-19 pandemic situation, if there is a lack of medical resources to protect patients from COVID-19 infection, it has been suggested that surgery could be replaced with concurrent chemoradiation therapy, radiation therapy or immunotherapy temporarily to slow disease progression ${ }^{8}$.

The current treatments for oral cavity cancer in Korea have not changed as a result of the COVID-19 pandemic.

In accordance with a report by Brody et al. ${ }^{4}$, a survey of 67 head and neck surgeons showed that, even during the COVID-19 pandemic, surgeons continued to recommend primary surgical treatment for oral cavity cancers, were least likely to be concerned for their own health and safety, and had the greatest concern for their resident trainees.

The results of the survey and the lack of change in the treatment of oral cavity cancer in Korea seems to demonstrate the unwavering attitude of surgeons during the COVID-19 pandemic.

As stated by one surgeon, 'We cannot stop despite the risks, as we must guarantee the best surgical treatment for these patients, and this is our contribution on these times of uncertainty" .

There is a high possibility that the COVID-19 pandemic will continue to increase in spread. Therefore, it is necessary to establish strategies and protocols for safety of patients, medical staff, and paramedical personnel. Social and institutional support for establishment and implementation of these strategies and protocols is necessary.

\section{Conflict of Interest}

No potential conflict of interest relevant to this article was reported.

\section{References}

1. World Health Organization (WHO). WHO coronavirus disease (COVID-19) dashboard [Internet]. Geneva: WHO [cited 2020 Dec 8]. Available from: https://covid19.who.int/.

2. Gómez I, Seoane J, Varela-Centelles P, Diz P, Takkouche B. Is diagnostic delay related to advanced-stage oral cancer? A metaanalysis. Eur J Oral Sci 2009;117:541-6. https://doi.org/10.1111/ j.1600-0722.2009.00672.x

3. Halboub E, Al-Maweri SA, Al-Soneidar WA. Utilization of COVID-19 testing for opportunistic screening of oral cancer. Oral Oncol 2020;106:104775. https://doi.org/10.1016/ j.oraloncology.2020.104775

4. Brody RM, Albergotti WG, Shimunov D, Nicolli E, Patel UA, Harris $\mathrm{BN}$, et al. Changes in head and neck oncologic practice during the COVID-19 pandemic. Head Neck 2020;42:1448-53. https://doi. org $/ 10.1002 /$ hed.26233

5. Gupta A, Arora V, Nair D, Agrawal N, Su YX, Holsinger FC, et al. Status and strategies for the management of head and neck cancer during COVID-19 pandemic: Indian scenario. Head Neck 2020;42:1460-5. https://doi.org/10.1002/hed.26227

6. Moon SS, Lee K, Park J, Yun S, Lee YS, Lee DS. Clinical characteristics and mortality predictors of COVID-19 patients hospitalized at nationally-designated treatment hospitals. J Korean Med Sci 2020;35:e328. https://doi.org/10.3346/jkms.2020.35.e328

7. Forner D, Noel CW, Wu V, Parmar A, Chan KKW, de Almeida JR, et al. Nonsurgical management of resectable oral cavity cancer in the wake of COVID-19: a rapid review and metaanalysis. Oral Oncol 2020;109:104849. https://doi.org/10.1016/ j.oraloncology.2020.104849

8. Chu C, Sun Y, Pan Y. Immunotherapy is a preferred option for oral cancer patients during COVID-19 pandemic? Oral Oncol 2020;107:104860. https://doi.org/10.1016/ j.oraloncology.2020.104860

9. Valentini V, Pucci R, Battisti A, Cassoni A. Head and neck cancer cannot wait for this pandemic to end: risks, challenges and perspectives of oral-maxillofacial surgeon during COVID-19. Oral Oncol 2020;106:104758. https://doi.org/10.1016/ j.oraloncology.2020.104758

How to cite this article: Park JY. Oral cavity cancer management during the COVID-19 pandemic. J Korean Assoc Oral Maxillofac Surg 2020;46:371-372. https://doi.org/10.5125/jkaoms.2020.46.6.371 